\title{
TDZ-Induced High Frequency Plant Regeneration through Direct Shoot Organogenesis in Stevia rebaudiana Bertoni: An Important Medicinal Plant and a Natural Sweetener
}

\author{
Hemant Lata ${ }^{1}$, Suman Chandra ${ }^{1}$, Yan-Hong Wang ${ }^{1}$, Vijayasankar Raman ${ }^{1}$, Ikhlas A. Khan ${ }^{1,2 *}$ \\ ${ }^{1}$ National Center for Natural Products Research, School of Pharmacy, The University of Mississippi, University, USA; ${ }^{2}$ Department \\ of Pharmacognosy, School of Pharmacy, The University of Mississippi, University, USA. \\ Email: ${ }^{*} i k h a n @ o l e m i s s . e d u$
}

Received October $20^{\text {th }}, 2012$; revised November $28^{\text {th }}, 2012$; accepted December $29^{\text {th }}, 2012$

\begin{abstract}
An efficient high frequency plant regeneration protocol through direct organogenesis was developed for Sevia rebaudiana Bert. Nodal segments containing axillary buds were used as an explant and inoculated on Murashige and Skoog's (MS) medium containing 3\% (w/v) sucrose, $0.8 \%(\mathrm{w} / \mathrm{v})$ agar supplemented with various concentrations of benzyladenine (BA), kinetin (Kn) and thidiazuron (TDZ) ranging from 1.00 to $9.00 \mu \mathrm{M}$. Maximum multiple shoots $(96 \%)$ were obtained in MS medium supplemented with $1.0 \mu \mathrm{M}$ TDZ with an average of 60 shoots per culture, having an average shoot length of $6.0 \mathrm{~cm}$. The best in vitro root induction (89\%) was achieved on half strength MS medium without any growth regulator with an average of 24 roots per culture and root length of $7 \mathrm{~cm}$. The rooted plantlets were successfully established in soil and grown to maturity at the survival rate of $95 \%$ in the indoor grow room. High- performance liquid chromatography was used to assess the stability in chemical profile and quantification of stevioside and rebaudioside A content of in vitro propagated S. rebaudiana plants and compared with their mother plant at the peak vegetative stage. Our results show no significant differences $(p<0.05)$ between the mother and in vitro propagated plants. Furthermore, fully developed in vitro propagated S. rebaudiana plants were also compared with mother plant for their gas and water vapour exchange characteristics and leaf anatomy. The results show that in vitro propagated and hardened plants of $S$. rebaudiana are morphologically as well as functionally comparable to each other and to their mother plant.
\end{abstract}

Keywords: Asteraceae; Gas and Water Vapour Exchange; In Vitro Propagation; Leaf Anatomy; Rebaudioside A; Stevia rebaudiana; Stevioside; Thidiazuron

\section{Introduction}

Stevia rebaudiana Bert. (Asteraceae) commonly known as a natural sweetner, is a zero calorie value natural alternative source to traditional sugar (sucrose) obtained from sugarcane, sugarbeet [1]. It is native from Paraguay and Southern Brazil, but is now cultivated on a commercial scale in other countries, particularly Japan, Taiwan, Korea, Thailand and Indonesia [2]. S. rebaudiana has also been used as a medicinal plant to cure many diseases like obesity, hypertension, heartburn, hypogylycemia and to lower the uric acid levels [3]. The S. rebaudiana leaves are a significant source of diterpene steviol glycosides that are about 300 times sweeter than sucrose at their concentration of $4 \%(\mathrm{w} / \mathrm{v})$ [4].

Recent studies have displayed a high degree of variability in sweetening level and composition due to the

${ }^{*}$ Corresponding author. heterogenous populations obtained through propagation by seed $[5,6]$. Vegetative propagation too is limited by the lower number of individuals that can be obtained simultaneously from a single plant due to pathogen accumulation in the tissues [7-9]. Therefore, clonal propagation is ideal to reduce some of these problems and micropropagation using plant tissue culture technology, offers an approach that is capable of producing large numbers of genetically similar, disease free $S$. rebaudiana plants in a short period of time and limited space. Although, there are several reports of micropropagation of $S$. rebaudiana $[6,8,10-12]$ available, in all the previous studies involving in vitro regeneration, BA was the choice as plant growth regulator. In addition, the number of shoots regenerated was comparatively low or the time taken for the plantlet formation was long. Therefore, there is a need to develop an improved and efficient protocol for the mass propagation of elite plants of $S$. re- 


\section{baudiana.}

Besides development of a novel micropropagation system, an efficient growth regulator capable of inducing high organogenesis is necessary. Thidiazuron (TDZ: Nphenyl-N-[1,2,3-thidiazol-5-yl)urea]), a non purine cytokinin compound, has been shown to exhibit a stronger effect than $\mathrm{N}^{6}$-benzyladenine (BA) on in vitro morphogenesis of a large number of plants [13-17]. In the present study, we report an efficient high frequency in vitro regeneration protocol using TDZ. Furthermore, metabolic profiling (HPLC analysis), eco-physiological (photosynthesis, transpiration, stomatal conductance, internal $\mathrm{CO}_{2}$ concentration and water use efficiency) and leaf anatomical (stomatal length, width, frequency and index, leaf transverse section, epidermal cells, palisade cells and spongy parenchyma cells) characteristics were also studied to determine the differences, if any, exists between mother plant and in vitro propagated and hardened $S$. rebaudiana plants.

\section{Material and Methods}

\subsection{Plant Material}

S. rebaudiana plants were generated through vegetative propagation from seed raised high yielding elite $S$. rebaudiana plant (screened and selected on the basis of its chemical profile using High Pressure Liquid Chromatography, HPLC). These plants were kept in a climatic controlled indoor cultivation facility housed at CoyWaller laboratory at the National Center for Natural Product Research, The University of Mississippi and served as mother plants for the micrpropagation experiments. Nodal segments from a single mother plant containing axillary buds $(\sim 1 \mathrm{~cm}$ in length) were used as an explant for initiation of shoot cultures.

\subsection{Sterilization}

Explants were surface disinfected using $0.5 \% \mathrm{NaOCl}$ $(15 \% \mathrm{v} / \mathrm{v}$ bleach) and $0.1 \%$ tween 20 for $20 \mathrm{~min}$. The explants were washed in sterile distilled water 3 times for 5 min prior to inoculation on the culture medium.

\subsection{Inoculation}

Disinfected explants were inoculated on Murashige and Skoog's (MS) medium (Murashige and Skoog, 1962) containing 3\% (w/v) sucrose, $0.8 \%(\mathrm{w} / \mathrm{v})$ Type E Agar (Sigma Chemical Co., St. Louis) supplemented with various concentrations of cytokinins-benzyladenine (BA), kinetin (Kn) and thidiazuron (TDZ) ranging from 1.0 to $9.0 \mu \mathrm{M}$ adjusted to $\mathrm{pH}$ 5.7. Sterile medium was dispensed $(25 \mathrm{ml})$ in glass culture vessels $(4 \mathrm{~cm}$ diameter $\times$ $9.5 \mathrm{~cm}$ high, jars with magenta B caps). Shoots that originated from the explants were subcultured after 30 days. The frequency with which explants produced shoots, the average number of shoots per explant and the shoot length were recorded after 30 days of culture.

Shoots taller than $\sim 5.0 \mathrm{~cm}$ were transferred to MS medium without growth regulator, half strength MS medium without growth regulator and MS medium with different auxins-Indole-3-acetic acid (IAA), Indole-3-butyric acid (IBA), Naphthalene acetic acid (NAA) at 0.5, 1.0 and 2.5 $\mu \mathrm{M}$ concentrations for root induction. All cultures were incubated at $25^{\circ} \mathrm{C} \pm 2^{\circ} \mathrm{C}$ with $16 \mathrm{~h}$ photoperiod under fluorescent light with a photon flux of $\sim 52 \mu \mathrm{mol} \mathrm{m}{ }^{-2} \cdot \mathrm{s}^{-1}$. All experiments were repeated at least 3 times with 9 explants, with one explant per jar. The cultures were observed constantly for any response. Data were recorded on the percentage of rooting, the mean number of roots per shoot and the root length after four weeks of transfer onto the rooting medium.

\subsection{Acclimatization}

Rooted shoots were carefully taken out of the medium and washed thoroughly in running tap water to remove all traces of medium attached. Plantlets were preincubated in coco natural growth medium (Canna Continental, Los Angeles, CA) in thermocol cups for 10 days. The cups were covered with polythene bags to maintain humidity and kept in a growroom and later acclimatized in sterile potting mixfertilome (Canna Continental) in large pots. All these plantlets were kept under similar environmental conditions grown in an indoor cultivation facility housed at Coy-Waller laboratory at The University of Mississippi. Light was provided with full spectrum 1000 watts HID (high density discharge) lamps (Sun Systems, CA) hung on the top of plants. A hot air suction fan was attached and about 1 meter distance between plants and bulb was maintained to avoid heating due to HID bulbs. Using an automatic electric timer artificial day/night cycle was regulated with a $16 \mathrm{~h}$ photoperiod. Growroom temperature and relative humidity was kept nearly $25^{\circ} \mathrm{C} \pm 2{ }^{\circ} \mathrm{C}$ and $60 \%$, respectively. Plants were watered regularly and individually to maintain sufficient moisture content in the pots.

\subsection{Comparison of in Vitro Propagated Plants with Mother Plant}

\subsubsection{Chemical Profile, Rebaudioside A and Stevioside Content}

Since stevioside concentrations in the $S$. rebaudiana leaves are reported to be maximum at peak vegetative stage i.e. just before flowering [18], leaf samples from mother plant and fully developed in vitro propagated plants were collected at that stage for the comparison. 
Dry powdered samples $(0.2 \mathrm{~g}$ each) were weighed and sonicated in $2.5 \mathrm{~mL}$ of $80 \%$ methanol $(\mathrm{MeOH} /$ water $=$ $80: 20, \mathrm{v} / \mathrm{v}$ ) at room temperature for $30 \mathrm{~min}$ followed by centrifugation for $10 \mathrm{~min}$ at $4000 \mathrm{rpm}$. The supernatant was transferred to a $10 \mathrm{~mL}$ volumetric flask. The procedure was repeated three times and respective supernatants combined. The final volume was adjusted to 10 $\mathrm{mL}$ with $80 \%$ methanol and mixed thoroughly. Prior to injection, an adequate volume (ca. $2 \mathrm{~mL}$ ) was passed through a $0.45 \mu \mathrm{m}$ nylon membrane filter. The first 1.0 $\mathrm{mL}$ was discarded and the remaining volume was collected in a LC sample vial. Standards rebaudioside A, stevioside and steviolbioside were isolated at NCNPR, the identity and purity was confirmed by chromatographic (TLC, HPLC) methods and by the analysis of the spectroscopic data (IR, 1D- and 2D-NMR, HRESI-MS). All HPLC analyses were applied on Waters Alliance 2695 HPLC system (Waters Corp., Milford, MA, USA) and a computerized data station using Waters Empower 2 software. A reverse phase Gemini C18 column $(250 \times 4.6 \mathrm{~mm}$ i.d., $5 \mu \mathrm{m}$ particle size $)$ from Phenomenex (Torrance, CA, USA) was used as the stationary phase and the temperature was maintained at $40^{\circ} \mathrm{C}$. The column was equipped with a $2 \mathrm{~cm} \mathrm{LC}-18$ guard column (Phenomenex, Torrance, CA, USA). The mobile phase consisted of water (A), acetonitrile/methanol (B), both containing $0.1 \%$ phosphoric acid. Analysis was performed using the following linear gradient elution at a flow rate of $0.7 \mathrm{~mL} /$ minute: $0-15 \mathrm{~min}, 58 \% \mathrm{~A} / 42 \% \mathrm{~B}$ to $42 \% \mathrm{~A} / 52 \% \mathrm{~B} ; 15-20,42 \% \mathrm{~A} / 52 \% \mathrm{~B}$ to $100 \% \mathrm{~B} ; 20-$ $25 \mathrm{~min}, 100 \% \mathrm{~B}$. The total run time was $25 \mathrm{~min}$. Each run was followed by a 5 min wash with $100 \%$ acetonitrile and an equilibration period of $15 \mathrm{~min}$. Ten microliters of sample was injected and detective wavelength was $205 \mathrm{~nm}$. Peaks were assigned by spiking the samples with standard compounds, comparison of UV spectra and the retention times.

\subsubsection{Eco-Physiological Parameters}

Plants regenerated from tissue culture and their mother plant was compared for their photosynthetic light response characteristics at their peak vegetative stage (just before initiation of flowers). Measurements were carried out on three upper undamaged, fully expanded and healthy leaves of five randomly selected in vitro propagated plants and their mother plant with the help of a closed portable photosynthesis system (Model LI-6400; LI-COR, Lincoln, Nebraska, USA). Leaves were exposed to $200,400,600,800,1000,1200,1400,1600$, 1800 and $2000 \mu \mathrm{mol} \mathrm{m} \mathrm{m}^{-2} \cdot \mathrm{s}^{-1}$ photon flux densities (PPFD) under controlled temperature $\left(25^{\circ} \mathrm{C} \pm 1{ }^{\circ} \mathrm{C}\right)$, humidity $(55 \% \pm 5 \%)$ and $\mathrm{CO}_{2}\left(350 \pm 5 \mu \mathrm{mol} \cdot \mathrm{mol}^{-1}\right)$ conditions. Light was provided with the help of an artificial light source (Model LI-6400-02; light emitting silicon diode; LI-COR), fixed on top of the leaf chamber and recorded with the help of quantum sensor kept in the range of 660 - $675 \mathrm{~nm}$, mounted at the leaf level. Temperature of the cuvette was controlled by integrated peltier coolers, which is controlled by the microprocessor. Control $\mathrm{CO}_{2}$ concentration was supplied to the cuvette of climatic unit (LI-6400-01, LI-COR Inc., USA) by mixing pure $\mathrm{CO}_{2}$ with $\mathrm{CO}_{2}$ free air and were measured by infrared gas analyzer. All the measurements for gas and water vapour exchange were first recorded at the lowest light condition and then subsequently to the increasing levels. Air flow rate $\left(500 \mathrm{mmol} \cdot \mathrm{s}^{-1}\right)$, temperature, humidity, $\mathrm{CO}_{2}$ concentration and relative humidity were kept constant throughout the experiment. Since steady state photosynthesis is reached within $30-45 \mathrm{~min}$, the leaves were kept for about $45-60 \mathrm{~min}$. under each set of light conditions before the observations were recorded. Four gas exchange parameters viz., photosynthetic rate $\left(P_{\mathrm{N}}\right)$, transpirational water loss $\left(T_{\mathrm{R}}\right)$, stomatal conductance $\left(g_{\mathrm{s}}\right)$ and intercellular $\mathrm{CO}_{2}$ concentration $\left(C_{\mathrm{i}}\right)$ were measured simultaneously at steady state condition under the each light level. Water use efficiency (WUE) was calculated as a ratio of the rate of photosynthesis and transpiration. Mean values $( \pm \mathrm{SE})$ of each parameters for mother plant $(n=9)$ and in vitro propagated plant $(n=18)$ were used for comparison.

\subsubsection{Anatomical Parameters}

Fully mature and healthy leaves (third to fifth from top downwards) were collected from in vitro propagated and their mother plant and were fixed in FAA for anatomical observations. Free hand sections of fresh leaf samples and those fixed in FAA were prepared using sharp razor blades. Thin sections were selected and cleared by heating in chloral hydrate, on a glass slide covered with a cover slip, and stained with phloroglucinol $+\mathrm{HCl}$. For epidermal studies, leaf pieces were cut from the mid part of leaf and directly placed on a glass slide. The sample was cut into two and one half turned over and placed next to the other in order to view both the surfaces, covered with chloral hydrate solution and a coverslip, and properly labeled [19]. The slide was then gently heated by passing over a hot air gun till forming of air bubble stopped and the specimen became translucent. For thicker samples, the leaf pieces were taken in a test tube containing chloral hydrate solution and boiled. Peeling of epidermis was done using razor blade and forceps. All the preparations were viewed under and photographed using Olympus BX41 (Japan) microscope equipped with Olympus DP71 digital camera system. Measurements of microscopic parameters were done using the Olympus-DP Controller application. Mean values $( \pm \mathrm{SE})$ of 
each parameters $(n=15)$ for mother plant and in vitro propagated plant were used for comparison.

\subsection{Statistical Analysis}

Statistical analysis of data on the effect of growth regulators on multiplication, shoot proliferation and root induction, and comparison of in vitro propagated plants with their mother plant in terms of \% rebaudioside A and stevioside content, gas and water vapour characteristics and anatomical parameters were done using SYSTAT (Systat Software Inc. San Jose, CA, USA) statistical software.

\section{Results and Discussion}

An in vitro propagation protocol for rapidly producing $S$. rebaudiana plantlets from nodal explants was developed (Figure 1). The effect of various concentrations of cytokinins, benzyladenine (BA), kinetin (Kn) and thidiazuron (TDZ) ranging from 1.0 to $9.0 \mu \mathrm{M}$ was examined. Of the three cytokinins used, TDZ at $1.0 \mu \mathrm{M}$ concentration was most effective (96\%) for shoot proliferation (Table 1). Several reports suggest that TDZ results in shoot regeneration better than other cytokinins [20-23]. According to Capelle et al. [23], TDZ directly promotes growth due to its own biological activities similar to that of an N-sub- stituted cytokinin or it may induce the synthesis and accumulation of an endogenous cytokinin. Our results show that TDZ at higher concentration than $1.0 \mu \mathrm{M}$ resulted in suppressed shoot formation. The superiority of lower concentration of TDZ has been well documented [24]. Mithila et al. [25] also reported shoot organogenesis at lower concentrations of TDZ in leaf explant cultures of African violet (Saintpaulia ionantha). The effectiveness of TDZ in promoting shoot formation in S. rebaudiana is precisely not known. In all the previous studies involving in vitro shoot regeneration of $S$. rebaudiana, BA was the choice of plant growth regulator where the shoot regeneration was either low or the time taken for the plantlet formation was rather long. In the present study use of TDZ in MS medium, overall, resulted in improvement in the number of shoots per explant and the average shoot length. Fully developed, healthy shoots were obtained within 4 weeks of initiation. The percent shoot regeneration $(60.31 \pm 5.42)$ and average shoot length $(6.24 \pm 0.52 \mathrm{~cm})$ was significantly higher $(p<0.05)$ in $1.0 \mu \mathrm{M} \mathrm{TDZ}$ treatment compared to that achieved with other concentrations of TDZ (Table 1).

For root induction, individual shoots or shoot clusters were transferred to full strength MS medium without growth regulators, half strength MS medium without
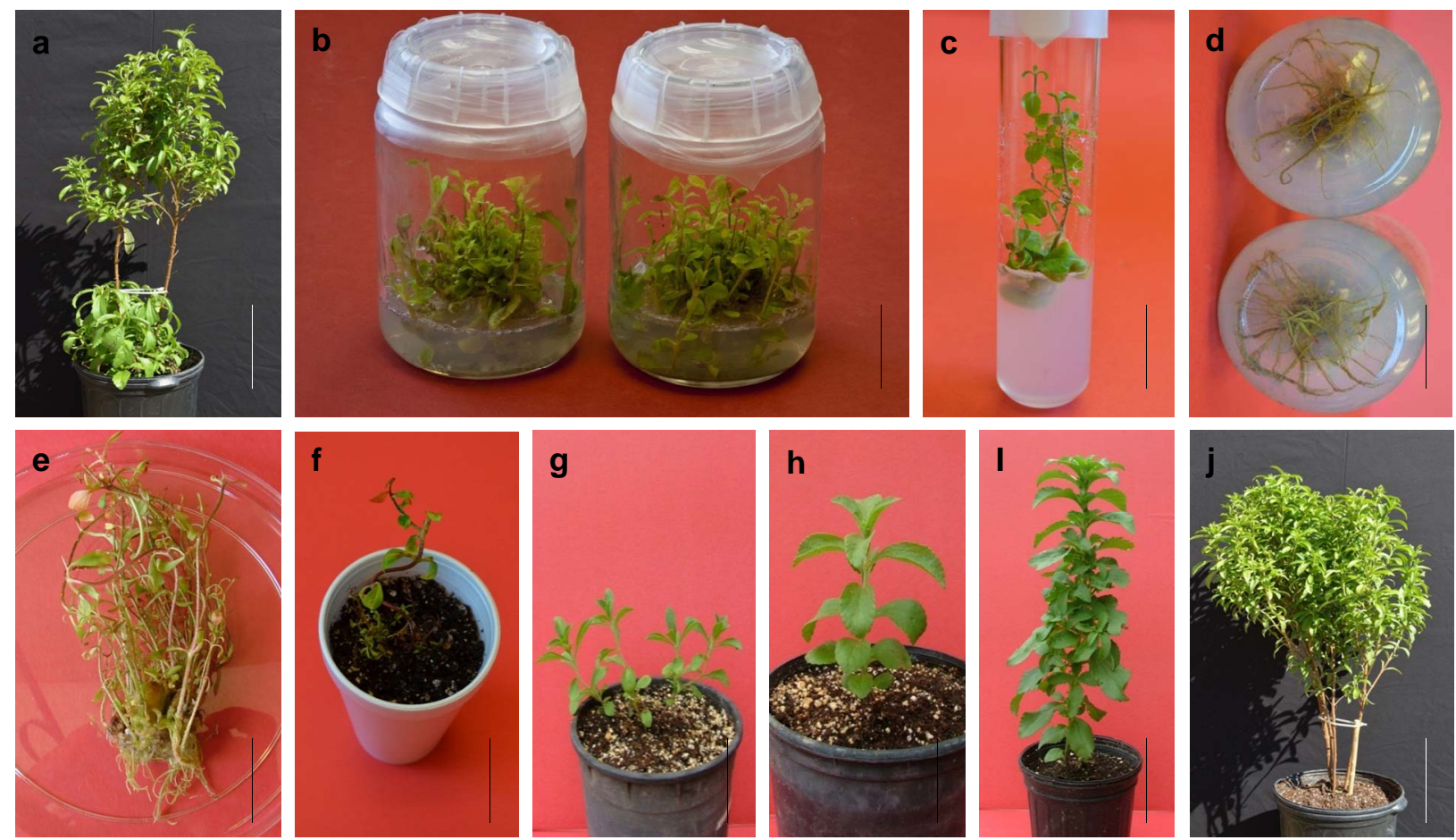

Figure 1. Micropropagation of Stevia rebaudiana using nodal segment. ((a) bar $6.00 \mathrm{~cm})$ mother plant, ((b) bar $8 \mathrm{~cm}$ and (c) bar $2.00 \mathrm{~cm}$ ) in vitro shoot multiplication, ((d) bar $1.71 \mathrm{~cm}$ and (e) bar $2.00 \mathrm{~cm})$ rooting, ((f) bar $2.30 \mathrm{~cm})$ fully rooted plant under acclimatization and hardening condition, ((g) bar $3.00 \mathrm{~cm},(\mathrm{~h})$ bar $3.47 \mathrm{~cm}$ and (i) bar $5.00 \mathrm{~cm}$ ) hardened tissue culture raised plant and ((j) bar $6.10 \mathrm{~cm})$ mature tissue culture raised plants. 
Table 1. The effect of different concentrations of cytokinins on multiple shoot formation and shoot length of Stevia rebaudiana.

\begin{tabular}{|c|c|c|c|c|c|}
\hline & $\begin{array}{l}\text { Concentration of Cytokinins } \\
(\mu \mathrm{M})\end{array}$ & & $\begin{array}{l}\text { \% Explants Forming } \\
\text { Multiple Shoots }\end{array}$ & $\begin{array}{l}\text { Average Number of Shoots per } \\
\text { Explants }\end{array}$ & $\begin{array}{c}\text { Average Shoot } \\
\text { Length }(\mathrm{cm})\end{array}$ \\
\hline TDZ & BAP & $\mathrm{Kn}$ & & & \\
\hline 1.0 & 0 & 0 & 96 & $60.31 \pm 5.42^{\mathrm{a}}$ & $6.24 \pm 0.52^{\mathrm{a}}$ \\
\hline 3.0 & 0 & 0 & 60 & $47.32 \pm 5.44^{\mathrm{b}}$ & $4.72 \pm 0.55^{\mathrm{b}}$ \\
\hline 5.0 & 0 & 0 & 52 & $42.43 \pm 4.76^{\mathrm{bc}}$ & $4.23 \pm 0.31^{\mathrm{bc}}$ \\
\hline 7.0 & 0 & 0 & 22 & $23.24 \pm 3.23^{\mathrm{de}}$ & $3.15 \pm 0.41^{\mathrm{cd}}$ \\
\hline 9.0 & 0 & 0 & 17 & $11.79 \pm 2.37^{\mathrm{ef}}$ & $2.23 \pm 0.37^{\mathrm{d}}$ \\
\hline 0 & 1.0 & 0 & 14 & $11.29 \pm 2.91^{\mathrm{ef}}$ & $3.25 \pm 0.17^{\mathrm{c}}$ \\
\hline 0 & 3.0 & 0 & 20 & $11.47 \pm 2.81^{\mathrm{ef}}$ & $3.19 \pm 0.21^{\mathrm{c}}$ \\
\hline 0 & 5.0 & 0 & 22 & $22.32 \pm 3.53^{\mathrm{de}}$ & $2.57 \pm 0.24^{\mathrm{d}}$ \\
\hline 0 & 7.0 & 0 & 40 & $24.17 \pm 3.92^{\mathrm{cd}}$ & $1.97 \pm 0.51^{\mathrm{de}}$ \\
\hline 0 & 9.0 & 0 & 48 & $32.72 \pm 4.98^{\mathrm{c}}$ & $2.45 \pm 0.24^{\mathrm{d}}$ \\
\hline 0 & 0 & 1.0 & 0 & $00.00 \pm 0.00^{\mathrm{g}}$ & $0.00 \pm 0.00^{f}$ \\
\hline 0 & 0 & 3.0 & 6 & $09.22 \pm 5.39^{\mathrm{f}}$ & $1.24 \pm 0.06^{\mathrm{def}}$ \\
\hline 0 & 0 & 5.0 & 8 & $11.58 \pm 2.46^{\mathrm{ef}}$ & $1.55 \pm 0.18^{\mathrm{def}}$ \\
\hline 0 & 0 & 7.0 & 12 & $16.38 \pm 2.59^{\text {def }}$ & $1.94 \pm 0.51^{\mathrm{de}}$ \\
\hline 0 & 0 & 9.0 & 30 & $22.12 \pm 4.25^{\mathrm{de}}$ & $2.15 \pm 0.42^{\mathrm{d}}$ \\
\hline
\end{tabular}

Values are mean \pm SE. $n=27$. Mean values in each column followed by the same letters (superscript) do not differ statistically at $p<0.05$. MS-Murashige and Skoog medium.

growth regulators and full strength MS medium supplemented with different concentrations of IAA, IBA or NAA ranging from $0.5 \mu \mathrm{M}$ to $2.5 \mu \mathrm{M}$ (Table 2). The best induction and growth of healthy roots in an optimal number ( $89 \%$ with $24.7 \pm 3.54$ roots per explant and 6.72 $\pm 0.81 \mathrm{~cm}$ average root length) was obtained in half strength MS medium without any growth regulator whereas, MS supplemented with growth regulators IAA, IBA or NAA, were less productive and the roots were of dawdling growth rate, thin and hairy. The competence of plant growth regulator free MS for in vitro rooting of $S$. rebaudiana has also been reported by others $[12,26]$. The regenerants induced from lower levels of TDZ developed roots sooner and grew faster than those obtained from higher concentrations. TDZ can subsititute both the auxin and cytokinin requirement and contribute to different modes of morphogenetic responses as organogenesis and somatic embryogenesis as reported by several authors [27-29]. The rooted plants exhibited $95 \%$ survival rate 8 weeks after transfer to the soil. The acclimatized plants exhibited normal development and no gross morphological variation was observed (Figure 1).

Chemical profile and, rebaudioside A and stevioside content of randomly selected few in vitro propagated plants and mother plant is shown in Figures $\mathbf{2}$ and 3, respectively. Our results show that chemical profiles of in vitro propagated plants were found similar to each other and to that of the mother plant assuring no somatic mutation occurred during the in vitro propagation process. Similarly, stevioside and rebaudioside A content in in vitro propagated plants were also highly comparable to each other and to that of mother plant. Out of seven randomly selected in vitro propagated plants tested, highest level of stevioside was found in plant ID P2 $(5.40 \% \pm$ $0.25 \%)$ and $\mathrm{P} 3(5.40 \% \pm 0.19 \%)$ whereas, minimum level of stevioside was found in P7 $(4.8 \pm 0.21)$. On the other hand, rebaudioside A content was highest in plant ID P1 $(3.42 \% \pm 0.12 \%)$ and minimum in P6 $(3.12 \% \pm$ $0.22 \%$ ). Stevioside and rebaudioside A content in the mother plant was tested $5.10 \% \pm 0.09 \%$ and $3.16 \% \pm$ $0.25 \%$, respectively. These minor differences in stevioside and rebaudioside A content were found statistically significant $(p<0.05)$, showing a high level of homology in these plants in terms of their major secondary metabolites.

Further, in vitro propagated plants were also compared 

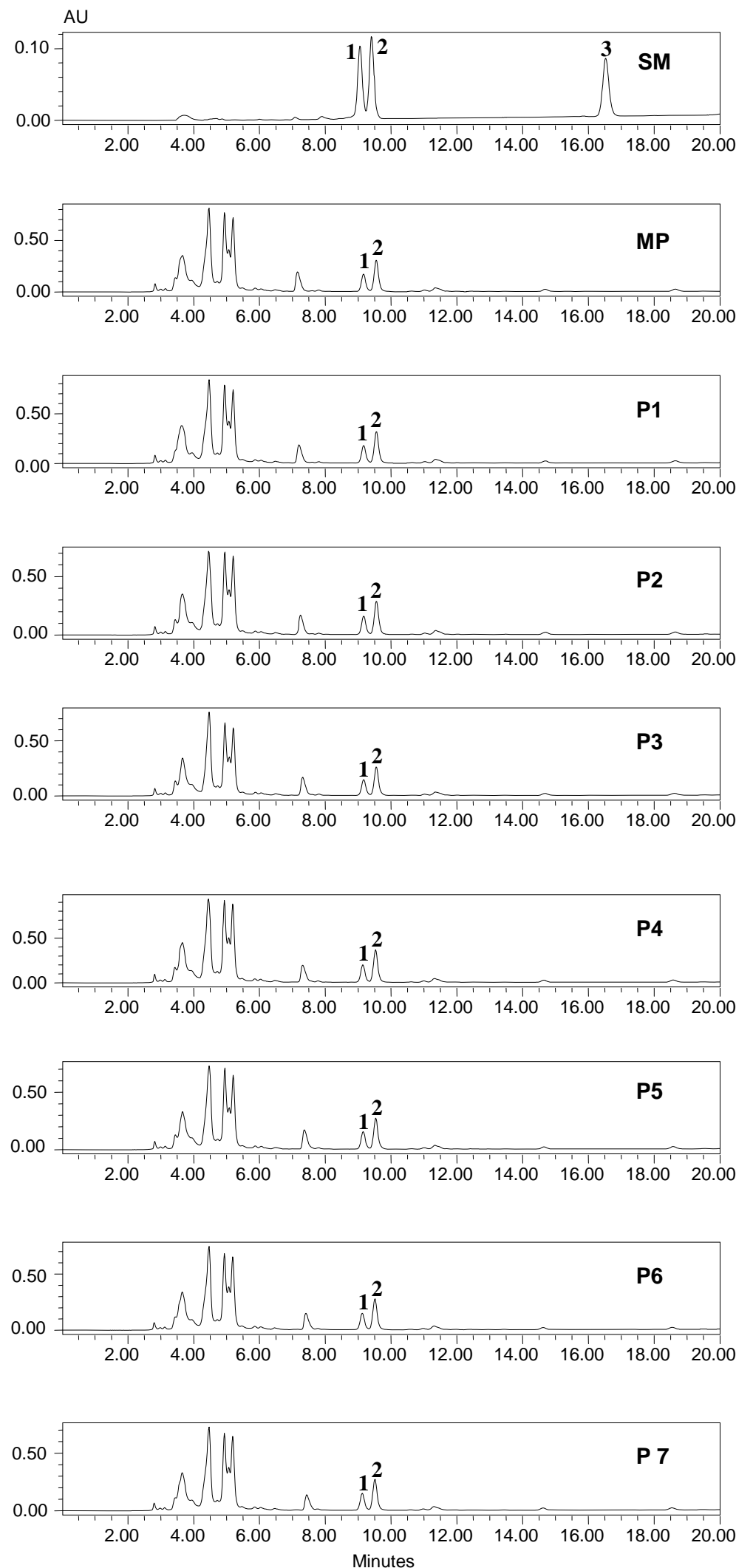

Figure 2. Metabolic profiling of mother plant (MP) and few randomly selected tissue culture propagated plants (P1 - P7) of Stevia rebaudiana. SM: Standard mix of rebaudioside A (peak 1), stevioside (peak 2) and steviolbioside (peak 3 ). 
TDZ-Induced High Frequency Plant Regeneration through Direct Shoot Organogenesis in Stevia rebaudiana Bertoni:

Table 2. The effect of different auxinsconcentrations on root induction from in vitro raised plants of Stevia rebaudiana.

\begin{tabular}{|c|c|c|c|c|c|c|}
\hline \multicolumn{4}{|c|}{$\begin{array}{l}\text { Concentrations of Auxins } \\
\qquad(\mu \mathrm{M})\end{array}$} & \multirow[t]{2}{*}{$\begin{array}{l}\text { \% Explants } \\
\text { Forming Roots }\end{array}$} & \multirow[t]{2}{*}{$\begin{array}{l}\text { Average Number of } \\
\text { Roots }\end{array}$} & \multirow[t]{2}{*}{$\begin{array}{l}\text { Average Root Length } \\
(\mathrm{cm})\end{array}$} \\
\hline & IAA & IBA & NAA & & & \\
\hline- & 0.5 & 0 & 0 & 43 & $6.23 \pm 0.44^{\text {cd }}$ & $2.17 \pm 0.32^{2^{e f}}$ \\
\hline- & 1.0 & 0 & 0 & 39 & $4.14 \pm 0.37^{\mathrm{de}}$ & $3.14 \pm 0.44^{\mathrm{de}}$ \\
\hline- & 2.5 & 0 & 0 & 33 & $4.52 \pm 0.46^{\mathrm{de}}$ & $2.15 \pm 0.37^{\mathrm{ef}}$ \\
\hline- & 0 & 0.5 & 0 & 48 & $5.72 \pm 0.67^{\mathrm{d}}$ & $2.23 \pm 0.64^{\mathrm{ef}}$ \\
\hline- & 0 & 1.0 & 0 & 38 & $3.12 \pm 0.73^{\mathrm{e}}$ & $3.14 \pm 0.55^{\mathrm{de}}$ \\
\hline- & 0 & 2.5 & 0 & 55 & $7.29 \pm 0.33^{\mathrm{c}}$ & $4.28 \pm 0.81^{\mathrm{bc}}$ \\
\hline- & 0 & 0 & 0.5 & 62 & $6.22 \pm 0.72^{\mathrm{cd}}$ & $3.36 \pm 0.41^{\mathrm{de}}$ \\
\hline- & 0 & 0 & 1.0 & 68 & $4.34 \pm 0.66^{\mathrm{de}}$ & $2.37 \pm 0.26^{\mathrm{e}}$ \\
\hline- & 0 & 0 & 2.5 & 63 & $5.37 \pm 0.83^{\mathrm{d}}$ & $3.42 \pm 0.29^{\mathrm{cd}}$ \\
\hline $\mathrm{MS}+\mathrm{NGR}$ & - & - & - & 75 & $16.39 \pm 2.11^{\mathrm{b}}$ & $4.57 \pm 0.44^{\mathrm{b}}$ \\
\hline $1 / 2 \mathrm{MS}+\mathrm{NGR}$ & - & - & - & 89 & $24.7 \pm 3.54^{\mathrm{a}}$ & $6.72 \pm 0.81^{\mathrm{a}}$ \\
\hline
\end{tabular}

Values are mean \pm SE. $n=27$. Mean values in each column followed by the same letters (superscript) do not differ statistically at $p<0.05$. MS-Murashige and Skoog medium, 1/2 MS: Half strength MS medium, NGR: No growth regulator.

with mother plant for their gas and water vapour exchange characteristics at different light levels (Figure 4). The effect of different photon flux densities on photosynthesis $\left(P_{\mathrm{N}}\right)$ is shown in Figure 4(a). Photosynthesis increased with increasing light intensity up to 1600 $\mu \mathrm{molm}{ }^{-2} \cdot \mathrm{s}^{-1}$ in mother plant as well as in vitro propagated plants. Maximum rate of photosynthesis $\left(P_{\mathrm{N} \text { max }}\right)$ was recorded to be $15.01 \pm 0.13 \mu \mathrm{molm}^{-2} \cdot \mathrm{s}^{-1}$ for the mother plant, whereas it was found to be slightly higher $16.28 \pm 0.29$ for in vitro propagated plants. Light saturation for $P_{\mathrm{N}}$ was recorded in the range of 1600 to 1800 $\mu$ molm ${ }^{-2} \cdot \mathrm{s}^{-1} \cdot \mathrm{CO}_{2}$ exchange was found to be adversely affected by light intensities $1800 \mu \mathrm{molm}^{-2} \cdot \mathrm{s}^{-1}$ in mother plant as well as in vitro propagated plants. The rate of transpiration $\left(T_{\mathrm{R}}\right)$ increased considerably, with an increase in light intensity (up to $2000 \mu \mathrm{molm}^{-2} \cdot \mathrm{s}^{-1}$ ) in both (the mother and in vitro propagated) types of plants (Figure 4(b)). Contrary to $T_{\mathrm{R}}$, stomatal conductance $\left(g_{\mathrm{s}}\right)$ was recorded highest at lowest light intensity for both mother $\left(320 \pm 23 \mu \mathrm{mol} \cdot \mathrm{mol}^{-1}\right)$ and in vitro propagated $\left(327 \pm 15 \mu \mathrm{mol} \cdot \mathrm{mol}^{-1}\right.$ ) plants (Figure 4(c)). A gradual decrease in $g_{\mathrm{s}}$ was observed in both types of plants with increasing light levels up to $2000 \mu \mathrm{molm}{ }^{-2} \cdot \mathrm{s}^{-1}$. Similarly, intercellular $\mathrm{CO}_{2}$ concentration $\left(C_{\mathrm{i}}\right.$, Figure 4(d)) and the ratio of intercellular $\mathrm{CO}_{2}$ concentration to ambient $\mathrm{CO}_{2}$ concentration $\left(C_{\mathrm{i}} / C_{\mathrm{a}}\right.$, Figure 4(e)) were recorded highest at lowest light intensity. A sudden decrease in $C_{\mathrm{i}}$ was observed with an increase in light intensity from 200 to $400 \mu \mathrm{molm}{ }^{-2} \cdot \mathrm{s}^{-1}$ and then became nearly constant in both types of plant at the light intensities higher than 400 $\mu \mathrm{molm}^{-2} \cdot \mathrm{s}^{-1}$. On the other hand, a gradual decrease in $C_{\mathrm{i}} / C_{\mathrm{a}}$ was observed in both types of plants with increasing light intensity up to $1000 \mu \mathrm{molm}^{-2} \cdot \mathrm{s}^{-1}$ and formed a plateau at the light intensities higher than 1000 $\mu \mathrm{molm}{ }^{-2} \cdot \mathrm{s}^{-1}$. A gradual increase in water use efficiency (WUE) in the mother plant and in vitro propagated plants was recorded with an increase in the light intensity up to $1400 \mu \mathrm{molm}^{-2} \cdot \mathrm{s}^{-1}$ and maximum values (mother plant, $2.74 \pm 0.10$; in vitro propagated plants, $2.72 \pm 0.18$ ) were recorded at this light intensity (Figure 4(f)). A decline in WUE was observed at light intensities higher than 1400 $\mu$ molm ${ }^{-2} \cdot \mathrm{s}^{-1}$ in both the sets of plants. Generally, a variation in the gas and water vapour characteristics reflects the adjustment of the plants to their respective growth environment. The data on gas and water vapour exchange for mother and in vitro propagated plants indicate that S. rebaudiana can survive light intensity of $\sim 1600$ $\mu \mathrm{molm}{ }^{-2} \cdot \mathrm{s}^{-1}$ PPFD, generally encountered under outdoor conditions during sunny days. Our results show that $P_{\mathrm{N}}$, $T_{\mathrm{R}}, C_{\mathrm{i}}, C_{\mathrm{i}} / C_{\mathrm{a}}$ and WUE of in vitro propagated plants were highly comparable to their mother plant. Thus, in vitro propagated plants would appear to be "normal" in respect of functional characteristics examined. A comparable photosynthetic activity between mother plant and in vitro 

An Important Medicinal Plant and a Natural Sweetener

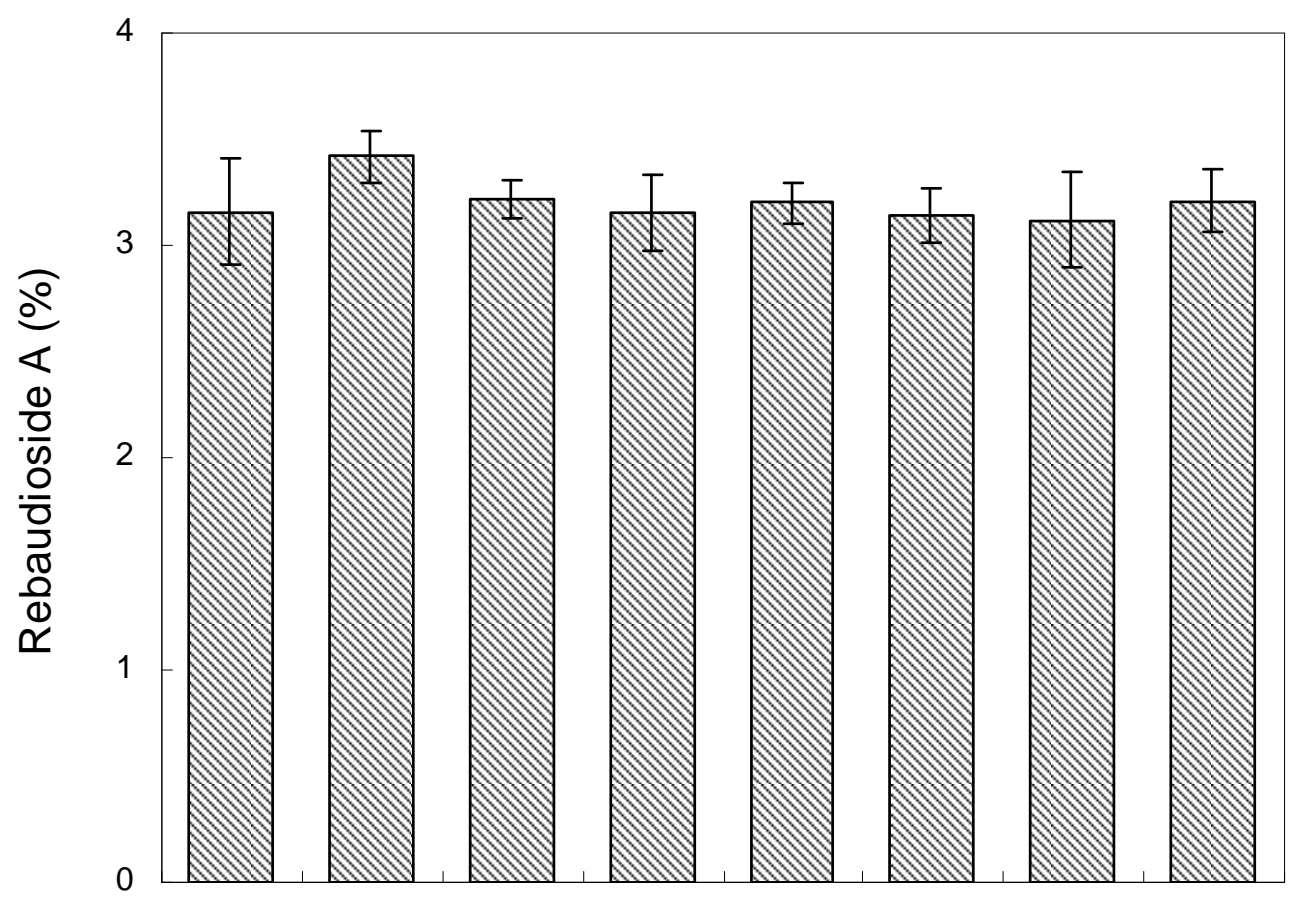

(a)

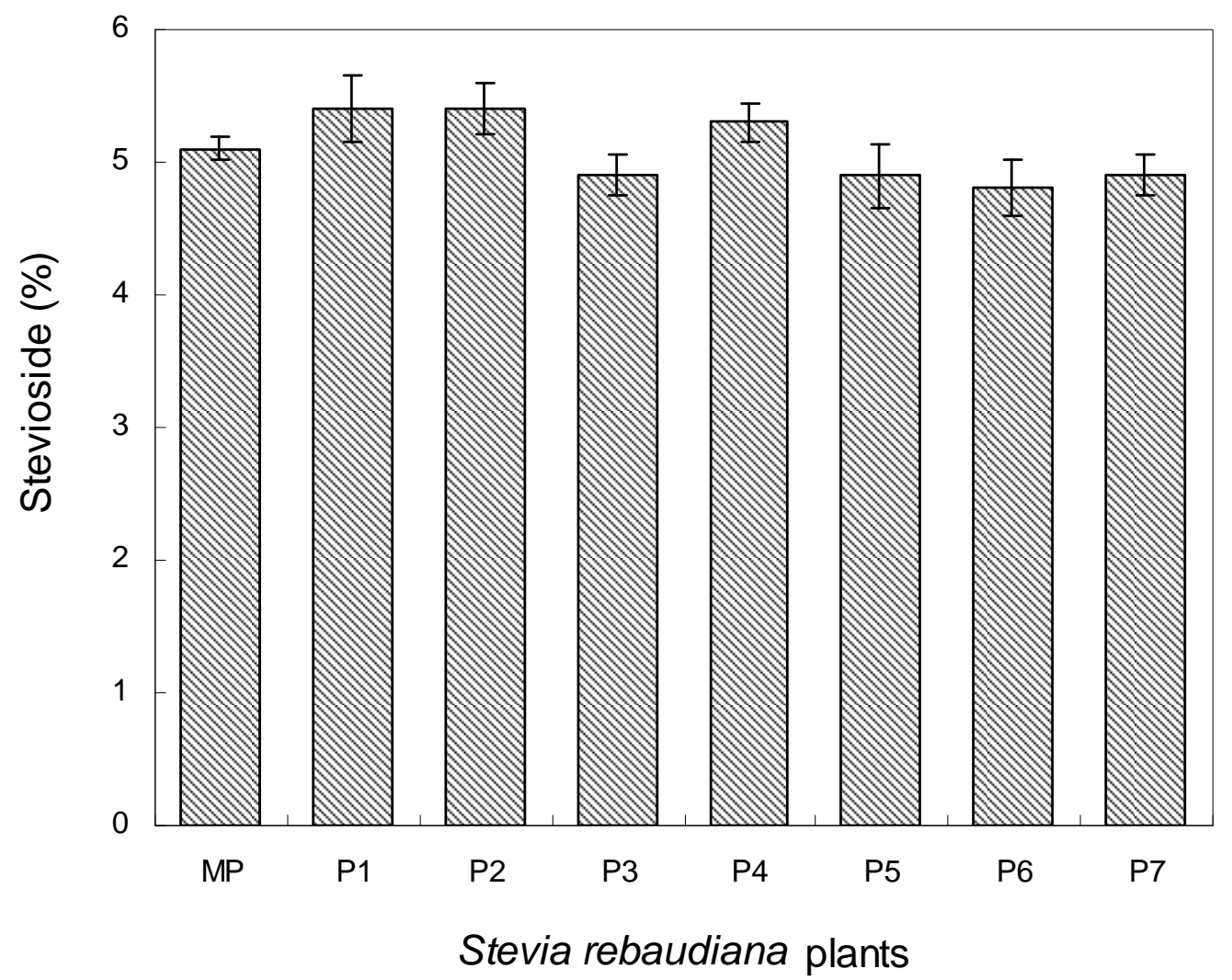

(b)

Figure 3. Percent (dry weight) Rebaudioside A (a) and Stevioside (b) content in the leaves of mother plant and fully developed randomly selected (P1 - P7, chemical profile are as shown in Figure 2) tissue culture raised plants of Stevia rebaudiana. $n=3$ \pm SE. LSD value $(p<0.05)$ is indicated by vertical bars. 


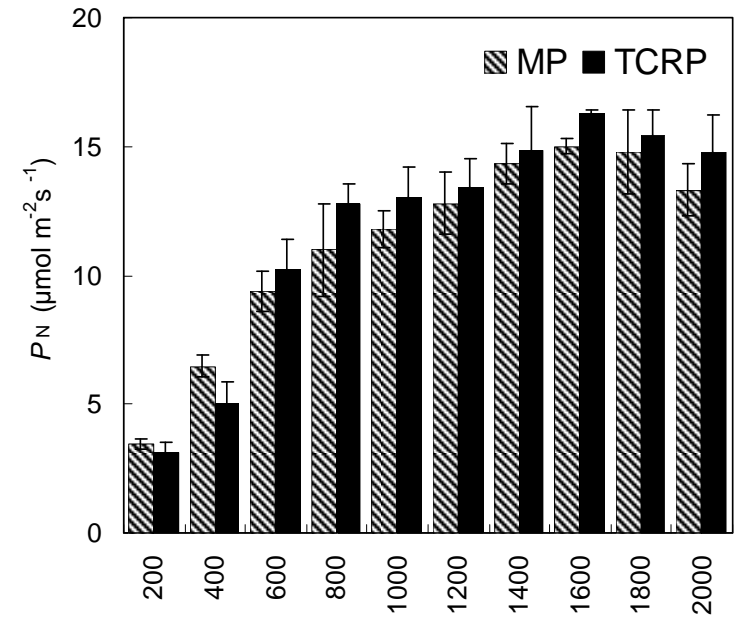

(a)

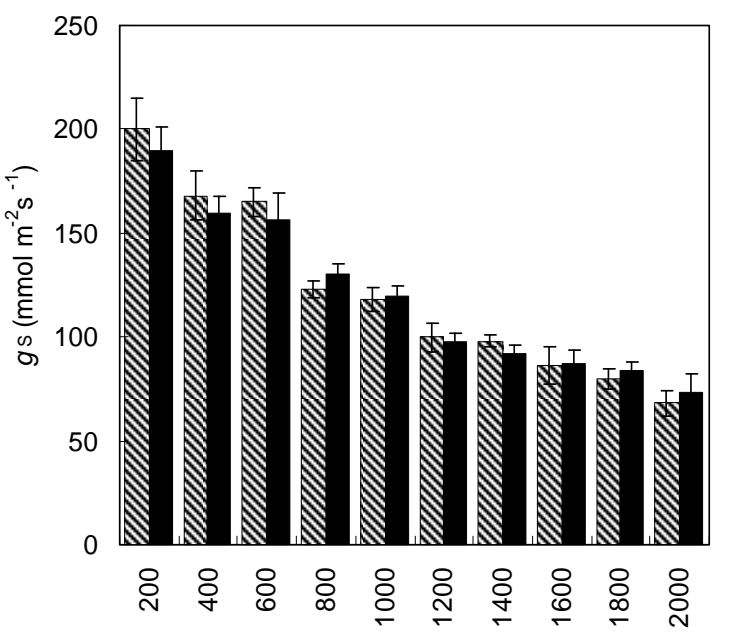

(c)

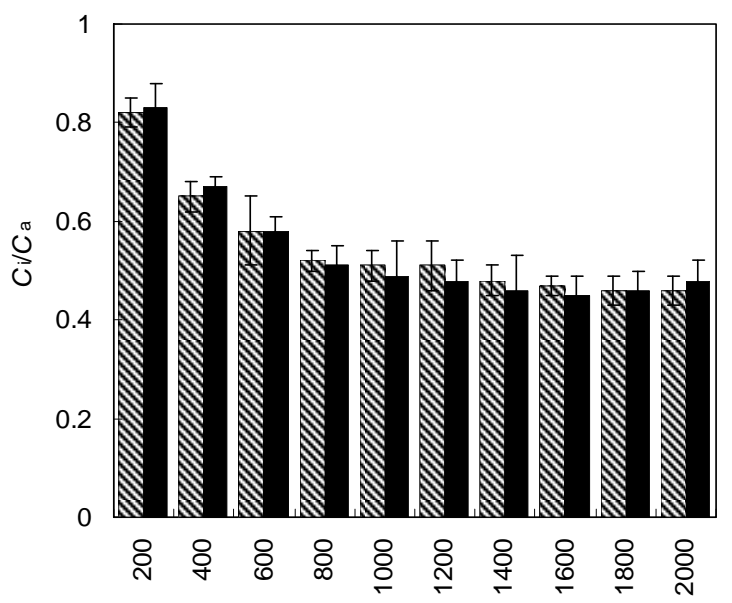

(e)

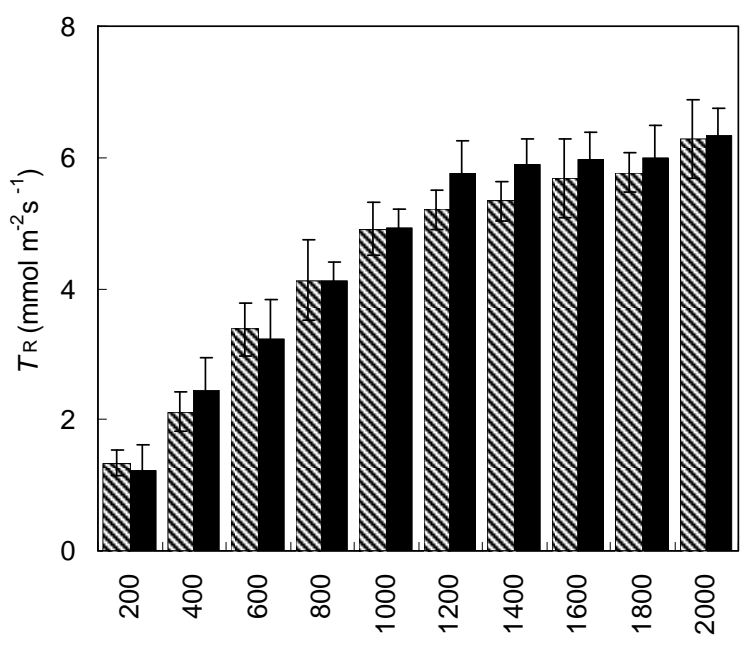

(b)

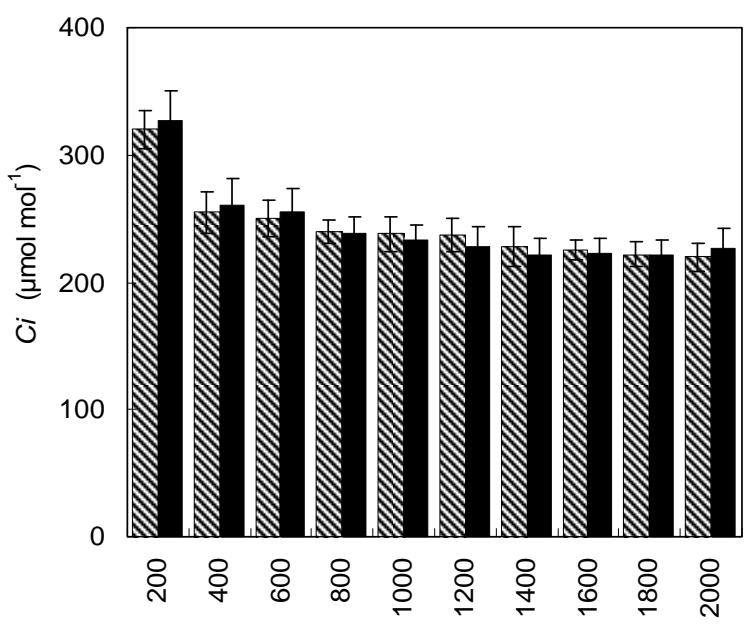

(d)

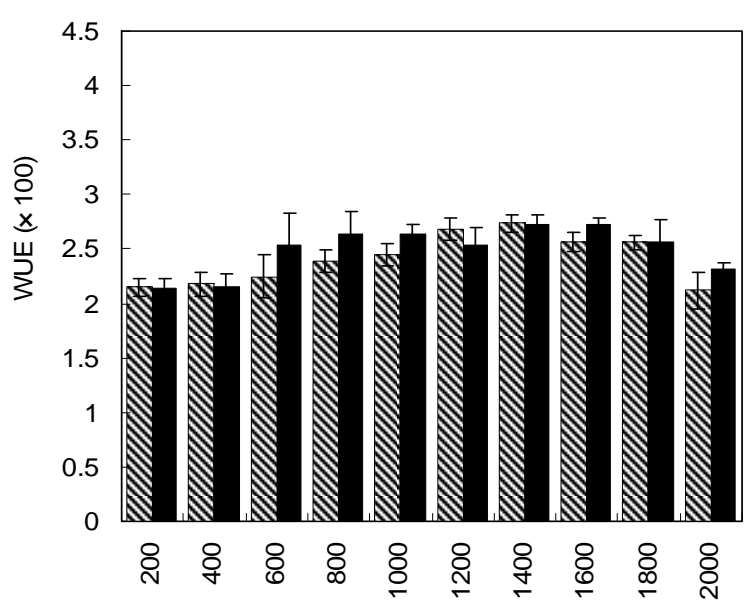

(f)

Figure 4. Comparison of gas and water vapour exchange characteristics of mother plant (MP, $n=9 \pm$ SE) and tissue culture raised plants (TCRP, $n=18 \pm \mathrm{SE}$ ) of Stevia rebaudiana. (a) $P_{\mathrm{N}}$, net photosynthesis; (b) $T_{\mathrm{R}}$, rate of transpiration; (c) $g_{\mathrm{s}}$, stomatal conductance; (d) $C_{\mathrm{i}}$, intercellular $\mathrm{CO}_{2}$ concentration; (e) $C_{\mathrm{i}} / C_{\mathrm{a}}$, inter cellular $\mathrm{CO}_{2}$ concentration to ambient $\mathrm{CO}_{2}$ and (f) WUE, water use efficiency. LSD $(p<0.05)$ is indicated by the vertical bars. 
propagated plants of same age has also been reported by Lata et al. [17], and Bag et al. [30] in Cannabis sativa and Dendrocalamus hamiltonii, respectively.

Comparison of leaf anatomical parameters of in vitro propagated plants and mother plant is shown in Table 3 and Figure 5. Average stomatal length, stomatal frequency, frequency of epidermis cells, stomatal index, width of adaxial epidermal cells, height and width of abaxial epidermal cells and, height and width of spongy parenchyma cells were measured slightly higher in the in

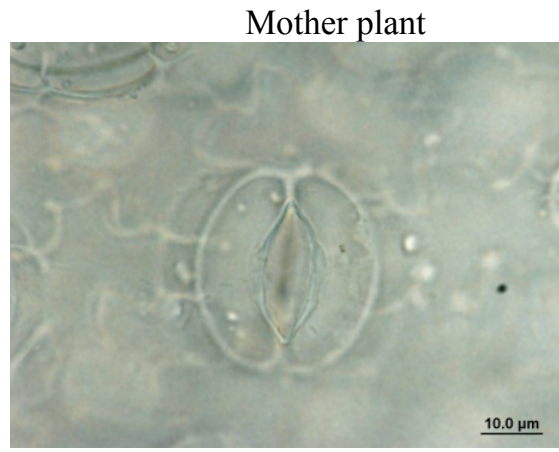

(a)

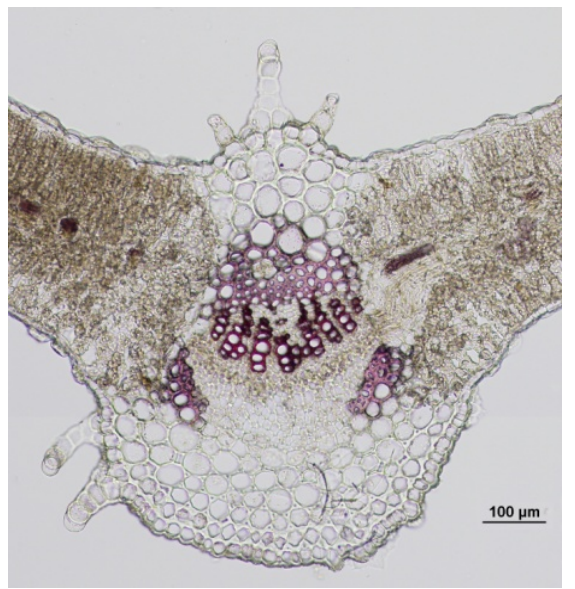

(c)

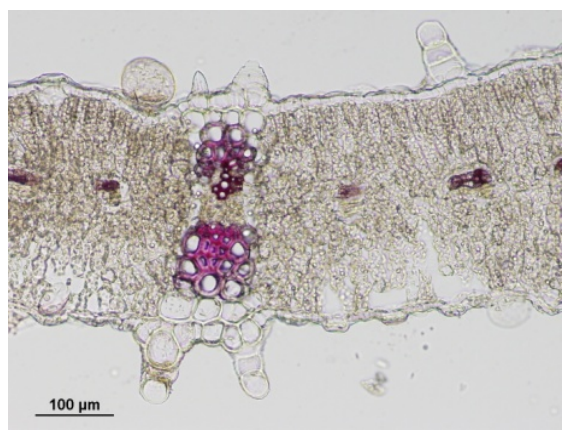

(e) vitro propagated plants, whereas, average stomatal width, thickness of leaf lamina, height of adaxial epidermal cells and, height and width of palisade cells were measured slightly higher in the mother plant as compared to the in vitro propagated plants. These differences, however, were not found statistically significant (Table 2, $p<$ $0.05)$. Similarly, no qualitative differences were observed in leaf stomata, transverse section leaf midrib and leaf lamina between the mother plant and in vitro propagated plants (Figure 5).

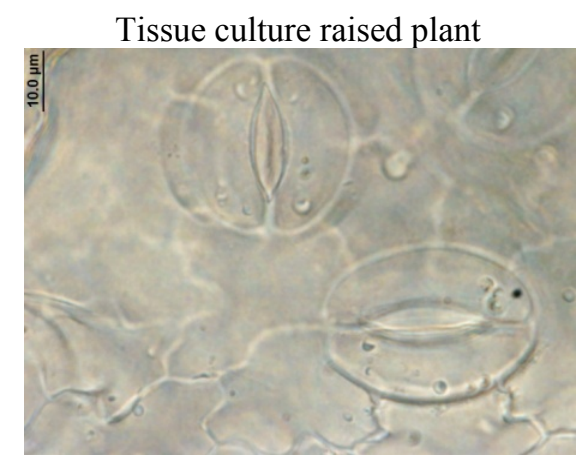

(b)

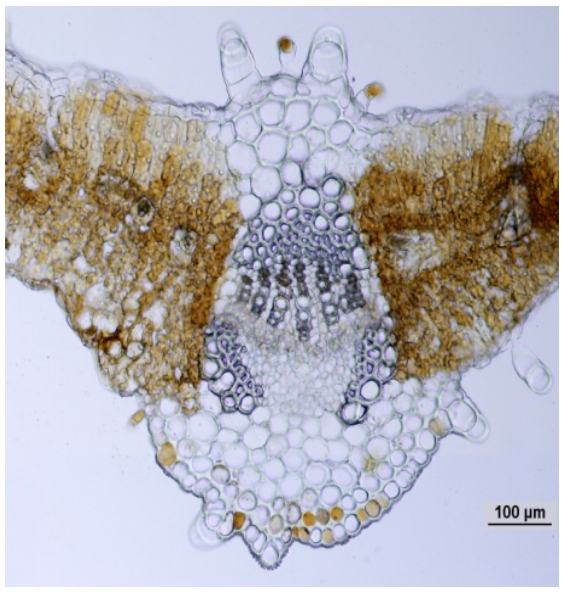

(d)

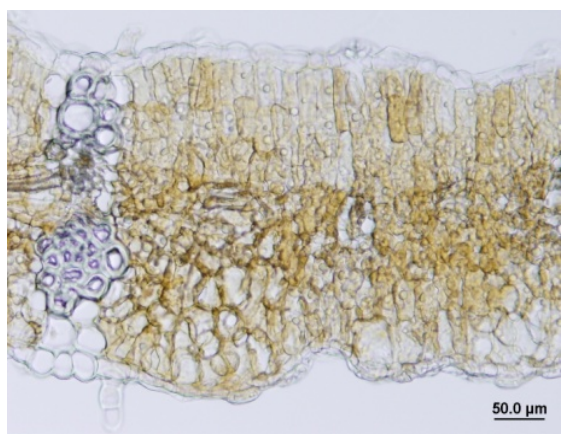

(f)

Figure 5. Leaf anatomical characteristics of mature mother plant (left column) and a representative tissue culture raised plant (right column). (a) and (b) leaf stomata, (c) and (d) transverse section of mature leaf, (e) and (f) transverse section of leaf lamina. 
Table 3. A comparison in leaf anatomical parameters of mother plantand randomly selected fully developed tissue culture raised plants. $n=15 \pm S E$.

\begin{tabular}{|c|c|c|c|c|}
\hline No. & Parameters & $\begin{array}{l}\text { Tissue culture raised } \\
\text { plants }\end{array}$ & $\begin{array}{l}\text { Mother } \\
\text { plant }\end{array}$ & $\begin{array}{c}\text { LSD } \\
(p<0.05)\end{array}$ \\
\hline 1 & Stomatal length $(\mu \mathrm{m})$ & $29.80 \pm 2.37$ & $29.50 \pm 3.29$ & 3.14 \\
\hline 2 & Stomatal width $(\mu \mathrm{m})$ & $25.81 \pm 3.18$ & $27.10 \pm 3.73$ & 4.12 \\
\hline 3 & Stomatal frequency (\# of stomata/200 $\mu \mathrm{mol} \mathrm{m}$ ) & $15.00 \pm 2.12$ & $13.00 \pm 1.82$ & 3.33 \\
\hline 4 & Frequency of epidermis cells (\# of cells $/ 200 \mu \mathrm{m}^{2}$ ) & $56.50 \pm 6.14$ & $56.00 \pm 4.00$ & 4.61 \\
\hline 5 & Stomatal index & $21.17 \pm 3.42$ & $18.80 \pm 2.34$ & 4.21 \\
\hline 6 & Thickness of leaf lamina $(\mu \mathrm{m})$ & $301.00 \pm 13.38$ & $312.00 \pm 26.13$ & 17.27 \\
\hline 7 & Height of adaxial epidermal cells $(\mu \mathrm{m})$ & $15.10 \pm 2.76$ & $16.10 \pm 3.54$ & 4.12 \\
\hline 8 & Width of adaxial epidermal cells $(\mu \mathrm{m})$ & $24.40 \pm 11.38$ & $22.80 \pm 9.28$ & 5.25 \\
\hline 9 & Height of abaxial epidermal cells $(\mu \mathrm{m})$ & $12.90 \pm 3.17$ & $11.70 \pm 2.51$ & 4.25 \\
\hline 10 & Width of abaxial epidermal cells $(\mu \mathrm{m})$ & $16.60 \pm 5.37$ & $17.20 \pm 4.85$ & 3.55 \\
\hline 11 & Height of palisade cells $(\mu \mathrm{m})$ & $47.60 \pm 8.78$ & $50.20 \pm 11.39$ & 4.92 \\
\hline 12 & Width of palisade cells $(\mu \mathrm{m})$ & $18.60 \pm 3.60$ & $22.00 \pm 3.54$ & 4.12 \\
\hline 13 & Height of spongy parenchyma cells $(\mu \mathrm{m})$ & $40.60 \pm 8.78$ & $33.30 \pm 10.5$ & 7.23 \\
\hline 14 & Width of spongy parenchyma cells ( $\mu \mathrm{m})$ & $21.00 \pm 4.39$ & $17.50 \pm 2.47$ & 5.24 \\
\hline
\end{tabular}

In conclusion, this study describes a rapid and highly efficient in vitro propagation protocol for S. rebaudiana. In vitro propagated plants appeared to be "normal" and highly comparable to each other and that of the mother plant in terms of their chemical profile, rebaudioside A and stevioside content, gas and water vapour exchange characteristics and in the leaf anatomy. The method therefore, can be used for mass propagation of S. rebaudiana for the industrial purpose.

\section{Acknowledgements}

This research was partially funded by a grant from the USDA, Agricultural Research Service Specific Cooperative Agreement No. 58-6408-7-012.

\section{REFERENCES}

[1] S. Bhosle, "Commercial Cultivation of Stevia rebaudiana," Agrobios Newsletter, Vol. 3, No. 2, 2004, pp. 4345.

[2] D. D. Soejarto, A. D. Kinghorn and N. R. Fransworth, "Potential Sweetening Agents of Plant Origin," Journal of Natural Products, Vol. 45, No. 5, 1982, pp. 590-599. doi: $10.1021 / \mathrm{np} 50023 \mathrm{a} 013$

[3] M. B. Ahmed, M. Salahin, R. Karim, M. A. Razvy, M. M, Hannan, R. Sultana, M. Hossain and R. Islam, "An Efficient Method for in Vitro Clonal Propagation of a Newly Introduced Sweetener Plant (Stevia rebaudiana) in Bangladesh," American-Eurasian Journal of Scientific Research,
Vol. 2, No. 2, 2007, pp. 121-125.

[4] N. Bondarev, O. Reshetnyak and A. Nosov, "Features of Development of Stevia rebaudiana Bertoni Shoots Cultivated in the Roller Bottle System and Their Production of Steviol Glycosides," Planta Medica, Vol. 68, No. 8, 2002, pp. 759-762. doi:10.1055/s-2002-33809

[5] H. Miyagawa and N. Fujioka, "Studies on The Tissue Culture of Stevia rebaudiana and Its Components: II. Induction of Shoot Primordia," Planta Medica, Vol. 52, No. 4, 1986, pp. 321-323. doi:10.1055/s-2007-969165

[6] M. Anbazhagan, M. Kalpana, R. Rajendran, V. Natrajan and D. Dhanavel, "In Vitro Production of Stevia rebaudiana Bertoni," Emirates Journal of Food and Agriculture, Vol. 22, No. 3, 2010, pp. 216-222.

[7] M. Sakaguchi and T. Kan, "Japanese Researches on Stevia rebaudiana," Ci Cult, Vol. 34, 1982, pp. 235-248.

[8] M. Debnath, "Clonal Propagation and Antimicrobial Activity of an Endemic Medicinal Plant Stevia rebaudiana," Journal of Medicinal Plants Research, Vol. 2, No. 2, 2008, pp. 45-51.

[9] P. K. Mishra, R. Singh, U. Kumar and V. Prakash, "Stevia rebaudiana-A Magical Sweetener," Global Journal of Biotechnology and Biochemstry, Vol. 5, No. 1, 2010, pp. 62-74.

[10] O. V. Kornilova and E. A. Kalashnikova, "Clonal Micropropagation of Stevia (Stevia rebaudiana)," Cercetari Agrton Moldova, Vol. 30, 1997, pp. 80-85.

[11] S. Verma, K. Yadav and N. Singh, "Optimization of the Protocols for Surface Sterilization, Regeneration and Acclimatization of Stevia rebaudiana Bertoni," Ameri- 
can-Eurasian Journal Agriculture and Environment Science, Vol. 11, No. 2, 2011, pp. 221-227.

[12] A. Das, S. Gantait and N. Mandal, "Micropropogation of an Elite Medicinal Plant (Stevia rebaudiana Bertoni)," International Journal of Agriculture Research, Vol. 6, No. 1, 2011, pp. 40-48. doi:10.3923/ijar.2011.40.48

[13] K. A. Malik and P. K. Saxena, "Thidiazuron Induces High Frequency Shoot Regeneration in Intact Seedlings of Pea (Pisum sativum) and Lentil (Lens culinaris)," Australian Journal of Plant Physiology, Vol. 19, No. 6, 1992, pp. 731-740. doi:10.1071/PP9920731

[14] B. Vinocur, T. Carmi, T. Altman and M. Ziv, "Enhanced Bud Regeneration in Aspen (Populus tremula L.) Roots Cultured in Liquid Media," Plant Cell Report, Vol. 19, No. 12, 2000, pp. 1146-1154. doi:10.1007/s002990000243

[15] S. Y. Park, H. N. Murth and K. Y. Paek, "Protocorm-Like Body Induction and Subsequent Plant Regeneration from Root Tip Cultures of Doritaenopsis," Plant Science, Vol. 164, No. 6, 2003, pp. 919-923. doi:10.1016/S0168-9452(03)00019-0

[16] G. Sujatha and R. B. D. Kumari, "High-Frequency Shoot Multiplication in Artemisia (Vulgaris L.) Using Thidiazuron," Journal of Plant Biotechnology Report, Vol. 1, No. 3, 2007, pp. 149-154. doi:10.1007/s11816-007-0028-1

[17] H. Lata, S. Chandra, I. Khan and M. A. ElSohly, "Thidiazuron Induced High Frequency Direct Shoot Organogenesis of Cannabis Sativa L.," In vitro Cellular and Developmental Biology-Plant, Vol. 45, No. 1, 2009, pp. 1219. doi:10.1007/s11627-008-9167-5

[18] S. D. Singh and G. P. Rao, "Stevia: The Herbal Sugar of 21st Century," Sugar Technology, Vol. 7, No. 1, 2005, pp. 17-24. doi:10.1007/BF02942413

[19] R. Upton, A. Graff, G. Jolliffe, R. Langer and E. Williamson, "American Herbal Pharmacopoeia: Botanical Pharmacognosy-Microscopic Characterization of Botanical Medicines," CRC Press, New York, 2011. doi: $10.1201 / \mathrm{b} 10413$

[20] T. D. Thomas and J. T. Puthur, "Thidiazuron Induced High Frequency Shoot Organogenesis in Callus from Kigelia pinnata L.," Botanical Bulltein of Academic Sinica, Vol. 45, No. 4, 2004, pp. 307-313.

[21] M. P. A. Jones, Z. Yi, S. J. Murch and P. K. Saxena, "Thidiazuron-Induced Regeneration of Echinacea purpurea L.: Micropropagation in Solid and Liquid Culture Systems," Plant Cell Reports, Vol. 26, No. 1, 2007, pp. 13-19. doi:10.1007/s00299-006-0209-3
[22] S. Parveen and A. Shahzad, "Thiadiazuron Induced High Frequency Shoot Regeneration in Cassia sophera L. via cotyledonary Node Explants," Journal of Plant Physiology and Molecular Biology, Vol. 16, No. 2, 2010, pp. 201-206. doi:10.1007/s12298-010-0022-x

[23] S. C. Capelle, D. W. S. Mok, S. C. Kirchner and M. C. Mok, "Effects of Thidiazuron on Cytokinin Autonomy and the Metabolism of N6-(Y2-Isopentyl) [8-14c] Adenosine in Callus Tissues of Phaseolus lunatus L.," Journal of Plant Physiology, Vol. 73, No. 3, 1983, pp. 796-802. doi:10.1104/pp.73.3.796

[24] C. Magioli, A. P. M. Rocha, D. E. de Oliveira and E. Mansur, "Efficient Shoot Organogenesis of Eggplant (Solanum melongena L.) Induced by Thidiazuron," Plant Cell Report, Vol. 17, No. 8, 1998, pp. 661-663. doi: $10.1007 / \mathrm{s} 002990050461$

[25] J. Mithila, J. C. Hall, J. M. R. Victor and P. K. Saxena, "Thidiazuron Induces Shoot Organogenesis at Low Concentrations and Somatic Embryogenesis at High Concentrations on Leaf and Petiole Explants of African Violet (Saintpaulia ionantha Wendl.)," Plant Cell Reports, Vol. 21, No. 5, 2003, pp. 408-414.

[26] J. C. Bespalhokk, L. G. E. Vicira and J. M. Hashimoto, "Embryogenic Callus Formation and Histological Studies from Stevia rebaudiana Bert. Floret Explants," Revista Brasileira de Fisiologia Vegetal, Vol. 5, 1997, pp. 51-53.

[27] C. Visser, J. K. Qureshi, R. Gill and P. K. Saxena, "Morphoregulatory Role of Thidiazuron: Substitution of AuxinCytokinin Requirement of Somatic Embryogenesis in Hypocotyl Cultures of Geranium," Journal of Plant Physiology, Vol. 99, No. 4, 1992, pp. 1704-1707. doi:10.1104/pp.99.4.1704

[28] B. N. S. Murthy, S. J. Murch, S. KrishnaRaj and P. K. Saxena, "Thidiazuron: A Potent Regulator of in Vitro Plant Morphogenesis," In Vitro Cellular Developmental Biology Plant, Vol. 34, No. 4, 1998, pp. 267-275. doi:10.1007/BF02822732

[29] R. Radhakrishnan, A. Ramachandran and B. D. R. Kumari, "Rooting and shooting: Dual function of Thidiazuron in Vitro Regeneration of Soybean (Glycine max. L.)," Acta Physiologiae Plantarum, Vol. 31, No. 6, 2009, pp. 12131217. doi:10.1007/s11738-009-0356-6

[30] N. Bag, L. M. S. Palni, S. Chandra and S. K. Nandi, "Somatic Embryogenesis in 'Maggar' Bamboo (Dendrocalamus hamiltonii) and Field Performance of Regenerated Plants," Current Science, Vol. 102, No. 9, 2012, pp. 1279-1287. 